IZA DP No. 1279

Migration and Diversity:

Human versus Social Capital

\author{
Vlad Manole \\ Maurice Schiff
}

August 2004 


\title{
Migration and Diversity: Human versus Social Capital
}

\author{
Vlad Manole \\ World Bank \\ Maurice Schiff \\ World Bank and IZA Bonn
}

Discussion Paper No. 1279

August 2004

\author{
IZA \\ P.O. Box 7240 \\ 53072 Bonn \\ Germany \\ Phone: +49-228-3894-0 \\ Fax: +49-228-3894-180 \\ Email: iza@iza.org
}

\begin{abstract}
Any opinions expressed here are those of the author(s) and not those of the institute. Research disseminated by IZA may include views on policy, but the institute itself takes no institutional policy positions.

The Institute for the Study of Labor (IZA) in Bonn is a local and virtual international research center and a place of communication between science, politics and business. IZA is an independent nonprofit company supported by Deutsche Post World Net. The center is associated with the University of Bonn and offers a stimulating research environment through its research networks, research support, and visitors and doctoral programs. IZA engages in (i) original and internationally competitive research in all fields of labor economics, (ii) development of policy concepts, and (iii) dissemination of research results and concepts to the interested public.
\end{abstract}

IZA Discussion Papers often represent preliminary work and are circulated to encourage discussion. Citation of such a paper should account for its provisional character. A revised version may be available directly from the author. 


\section{ABSTRACT \\ Migration and Diversity: Human versus Social Capital ${ }^{*}$}

This paper examines the welfare implications associated with different degrees of diversity or similarity between migrants and natives under both migration and trade. We use a general equilibrium model of migration, human capital and social capital and find that there are three equilibrium solutions: an internal one with half the population of each country migrating to the other country, and two corner solutions where everyone ends up in one of the two countries. The internal solution is unstable and is unlikely to be reached under different levels of human capital across the two countries. The corner solutions are stable and will be reached under most circumstances. If there are human capital differences across the two populations, everyone ends up in the country with the highest initial level of human capital. Welfare under any of the equilibrium solutions rises with the diversity in human capital and decreases with the diversity in social capital between migrants and natives. Trade and both migration solutions reduce inequality between the populations of the two countries by the same amount. In addition, trade and migration are not equivalent if social capital is present: the highest welfare is obtained with migration under the corner solution, the second highest welfare is obtained with trade, and the lowest welfare is obtained with migration under the internal solution. The first two solutions (third solution) raise (may raise or reduce) welfare relative to the no-migration case.

JEL Classification: F11, F16, F22, J61

Keywords: migration, trade, social capital, human capital, welfare

Corresponding author:

Maurice Schiff

Development Research Group

The World Bank

Mailstop No. MC3-303

$1818 \mathrm{H}$. St. NW

Washington DC 20433

USA

Email: mschiff@worldbank.org

\footnotetext{
* The opinions expressed in this paper are entirely those of the authors. They do not necessarily represent the view of the World Bank, its Executive Directors, or the countries they represent.
} 


\section{Introduction}

Employers in industrial countries tend to prefer immigrants with different skills from those of natives. Policy makers often go along, first, because of employer pressure, and second, because a greater diversity of skills enables increased gains from specialization and exchange. In other words, there is a preference for importing those skills that are in relatively short supply and are different from those with which natives are abundantly endowed.

The preference for immigrants with a different skill composition than that of natives applies to those with high skill levels, such as Indian software engineers in the US and Germany ${ }^{1}$, and to those with intermediate skill levels, such as Southern and Eastern African nurses in the UK. Another aspect of the preference for immigrants who differ from natives is the demand for unskilled workers to carry out low-end jobs that natives are unwilling to do (e.g., in the hotel and restaurant industries, agriculture, house cleaning and more).

On the other hand, policy makers have often implemented migration policies that discriminate in favor of people with an ethnic, cultural, religious or language background that is similar to that of natives. This includes Australia, which long favored immigration from the UK and where New Zealanders can still immigrate freely (Corden 2003), and the US where early immigration policies favored those with European background and discriminated against others, as documented by Jacobson (1998).

\footnotetext{
${ }^{1}$ Bauer and Kunze, 2004, present several initiatives to attract high skilled workers in OECD countries. Some countries, like Canada and Australia, increased the number of immigration quotas. Similarly, the U.S significantly increased the number of H1B-visas (temporary visas that are used by high skilled workers). In August 2001, Germany introduced the Green Card program, facilitating temporary visas for IT specialists (a quota of 20000 visas for a maximum of five years). Other countries reduced the transaction costs associated with the visa process. The U.K. reduced the requirements for high skilled visa. Starting in January 2002, France streamlined the process of obtaining visas for high skilled workers.
} 
Thus, on the one hand, migration policy seems to favor diversity between immigrants and natives, while on the other, it tends to favor similarity. The desire for similarity tends to be associated with social capital characteristics of migrants and natives, while the desire for diversity tends to be associated with their human capital characteristics. ${ }^{2}$ The model presented in this paper incorporates characteristics of both social and human capital in the production function in a two-country general equilibrium framework. It assumes that social capital raises productivity and falls with labor mobility and migration. Evidence on these relationships is provided in Schiff (2004). The above implies that migration generates externalities associated with social capital. The paper examines the welfare implications of different degrees of diversity or similarity between migrants and natives under both migration and trade.

The main findings are:

1. There are three equilibrium solutions: an internal one with half the population of each country migrating to the other country, and two corner solutions where everyone ends up in one of the two countries.

2. Welfare under any of the equilibrium solutions goes up as the diversity in social capital between migrants and natives decreases and that in human capital increases.

\footnotetext{
${ }^{2}$ Social capital has been defined as "the ability of people to work together for common purposes in groups or organizations" (Coleman, 1988) or as "... the set of elements of the social structure that affects relations among people and are inputs or arguments of the utility and/or production function" (Schiff, 1992). These elements include social norms, attitudes, values, language and culture. Social capital in the form of close ties to the community may generate benefits by raising utility directly, and/or by raising output through a reduction in the cost of transacting business due to higher trust and enforceability of sanctions. This paper focuses on the latter. For migration models focusing on the impact of social capital on utility, see Schiff (2002).
} 
3. Either of the two corner solutions maximizes world welfare. These solutions are obtained if immigration is unrestricted and there are high human capital differences between the two countries, or in the presence of social capital, if migration is fully restricted by one of the two countries.

4. The welfare impact of migration under the internal equilibrium solution is ambiguous.

5. Welfare increases with free trade and is higher than under the internal migration solution and lower than under the corner solutions. Consequently, trade and migration are not equivalent in the presence of social capital.

6. Both trade and migration reduce inequality between the populations of the two countries.

The remainder of the paper is organized as follows. Section 2 presents the model. Section 3 solves the model in the absence of migration and Section 4 does the same under migration. Section 5 presents the free trade solution and Section 6 compares the migration and free trade solutions. Section 7 examines migration dynamics and Section 8 concludes. 


\section{The Model}

The model draws in part on Schiff (2004) but differs by providing a more rigorous modeling of the social capital. This leads to solutions and implications that differ entirely from Schiff (2004).

Assume two "islands" $i=1,2$. Two-way migration can be obtained by assuming different endowments of industry-specific skills in each island, zero cross-island moving costs for labor and prohibitive moving costs for goods. Assume that the initial population on each island is $n=1$. Denote by $n_{i j}$ the proportion of natives of Island $i$ living on Island $j(i, j=1,2)$. Before migration takes place, $n_{11}=n_{22}=1$, and the proportion that migrates $n_{12}=n_{21}=0$.

Each native of Island $i$ living on Island $j$ consumes $X_{i j}$ and $Y_{i j}$ units of goods $X$ and $Y$, with utility given by

$$
U_{i j}=X_{i j}{ }^{\beta}+Y_{i j}^{\beta}, \quad \beta<1
$$

Note that a decrease in $\beta$ increases the gains from diversification of consumption. Output of $X$ and $Y$ depends on human capital and on local public goods and services whose provision is positively related to the level of social capital. Alternatively, assume that output depends on human capital and on aspects of social capital such as the extent of trust and cooperation among individuals. Thus, $X(Y)$ is produced with human capital or skill $x(y)$ and social capital $S$. Natives of Island 1 (2) are endowed with skill $x(y)$ and produce $X(Y){ }^{3}$ Given that the population of each island only has one skill and produces only one good, $\beta$ is also inversely related to the diversity in endowments of skills or

\footnotetext{
${ }^{3}$ For simplicity, the paper assumes one skill per island. The qualitative results hold if each island is endowed with both skills, as long as the skills ratios differ across the islands.
} 
human capital. ${ }^{4}$ Thus the gains from consumption diversification increase with the diversity in endowments. The production functions for $X$ and $Y$ are $\bar{X}_{1 j}=F\left(x, S_{1 j}\right)$ and $\bar{Y}_{2 j}=F\left(y, S_{2 j}\right)$, where $S_{i j}$ is the social capital available to individual $I_{i j}$. Specifically,

$$
\bar{X}_{1 j}=x S_{1 j}, \quad \bar{Y}_{2 j}=y S_{2 j} ; \quad j=1,2 .^{5}
$$

Following Lazear (2000), assume that the social capital is characterized by 'network' externalities (as with language), i.e., it increases with the number of people who share it . An individual $I_{i j}$ moving from Island $i$ to Island $j$ does not benefit from interaction with natives of Island $j$ to the extent that the natives of Island $j$ benefit because creating a network of social relations and building trust takes time, and some relations and experiences (e.g., those with family and childhood friends) cannot be recreated. Another reason might be that natives of Island $i$ may speak a different language than those in Island $j$. The islands may also differ in other aspects, including ethnicity and race. Glaeser et al. (2000) examined determinants of trust and trustworthiness in an experiment with 258 Harvard undergraduates and found that differences in nationality and race reduce the level of trustworthiness. Hence, migrants are assumed to gain partial access to the social capital of natives in their island of destination. Symmetrically, natives are assumed to gain partial access to the social capital of migrants to their own island. Specifically, the social capital available to a native $I_{i i}$ (who does not migrate) is $S_{i i}=n_{i i}+\alpha n_{i j},(i \neq j)$ and for a migrant from Island $i$ to Island $j(i \neq j)$ is $S_{i j}=n_{i j}+\alpha n_{j j}, \alpha \leq 1$.

\footnotetext{
${ }^{4}$ Note that implicitly human capital has two dimensions. The first is the level of $x$ and $y$ (highly skilled or not), and the second is the diversity between $x$ and $y$ as represented by $\beta$ (no diversity if both $x$ and $y$ are, say, farmers ( $\beta$ close to 1$)$, and greater diversity if $x$ is farmer and $y$ is engineer ( $\beta$ close to zero)).

${ }^{5}$ We have assumed here that social capital enters the production function and not the utility function. Assuming the latter — as in Schiff $(1998 ; 2002)$ and Schiff and Winters (1998)—does not change the main findings.
} 
Given these assumptions and equation (2), individual output is:

$$
\bar{X}_{11}=x\left(n_{11}+\alpha n_{21}\right) ; \bar{Y}_{22}=y\left(n_{22}+\alpha n_{12}\right) ; \bar{X}_{12}=x\left(n_{12}+\alpha n_{22}\right) ; \bar{Y}_{21}=y\left(n_{21}+\alpha n_{11}\right)
$$

\section{No Migration}

In the absence of migration, $i=j$ and $n_{11}=n_{22}=1$. Assuming prohibitive transport costs for goods, $X$ and $Y$ are not traded (this assumption is relaxed in Section 5).

Thus, quantities consumed $\left(X_{i j}, Y_{i j}\right)$ equal quantities produced $\left(\bar{X}_{i j}, \bar{Y}_{i j}\right)$. From the relations (3), these are $X_{11}=\bar{X}_{11}=x ; Y_{22}=\bar{Y}_{22}=y$ and $Y_{21}=\bar{Y}_{21}=Y_{12}=\bar{Y}_{12}=0$. From equation (1), utility is $U_{11}=x^{\beta}$ and $U_{22}=y^{\beta}$.

\section{Migration}

The natives of Island 1 (2) consume no $Y(X)$ and the relative price of $Y(X)$ in units of $X(Y)$ on Island 1 (2) is infinite (see equation (18) in Section 5). Thus there is an incentive to migrate in both directions. Assume now that the two islands sign a treaty integrating their labor markets by allowing free movement of people between them. People from Island $1(2)$ take their skills $x(y)$ to Island $2(1)$ in order to produce $X(Y)$ there and exchange part of it for $Y(X)$. Because people migrate in both directions, goods $X$ and $Y$ are now available on both islands.

Migration has three effects on welfare. First, since both $X$ and $Y$ are now produced and consumed on both islands, everyone benefits from diversification of consumption. 
On the other hand, migration leads to a private loss of productive skills, because migration leads to a decrease in one's own population and thus in social capital in the island of origin. At the same time migration raises one's own population in the island of destination and raises social capital there.

Assume good $Y$ is the numeraire. Natives and migrants maximize their utility, i.e. individuals from Island $1(2)$ maximize $U_{l j}\left(U_{2 j}\right), j=1,2$.

Consider Island 1 . The first order condition for natives and migrants are:

1.a $\quad X_{11}^{\beta-1}=Y_{11}^{\beta-1} \cdot P_{1}$

1.b $\quad X_{21}^{\beta-1}=Y_{21}^{\beta-1} \cdot P_{1}$,

where $P_{j}$ is the relative price of $X$ (in terms of $Y$ ) on Island $j$.

Budget constraints for natives and migrants are:

1.c

$P_{1} X_{11}+Y_{11}=P_{1} x\left(n_{11}+\alpha \cdot n_{21}\right)$

1.d

$$
P_{1} X_{21}+Y_{21}=y\left(n_{21}+\alpha \cdot n_{11}\right)
$$

Market clearing conditions for goods $X$ and $Y$ are ${ }^{6}$ :

1.e

$$
n_{11} X_{11}+n_{21} X_{21}=n_{11} x\left(n_{11}+\alpha n_{21}\right)
$$

$$
n_{11} Y_{11}+n_{21} Y_{21}=n_{21} y\left(n_{21}+\alpha n_{21}\right)
$$

The same conditions hold for Island 2, namely:

$$
\begin{array}{ll}
2 . a & X_{22}^{\beta-1}=Y_{22}^{\beta-1} \cdot P_{2} \\
2 . b & X_{12}^{\beta-1}=Y_{12}^{\beta-1} \cdot P_{2} \\
\text { 2.c } & P_{2} X_{12}+Y_{12}=P_{2} x\left(n_{12}+\alpha \cdot n_{22}\right)
\end{array}
$$

\footnotetext{
${ }^{6}$ Equation (1.f) is not independent of equations (1.c), (1.d) and (1.e) (Walras Law).
} 
Population identity:

$$
\begin{array}{ll}
\text { 3. } a & n_{11}+n_{12}=1 \\
3 . b & n_{21}+n_{22}=1
\end{array}
$$

Internal migration equilibrium is obtained when the migrants and natives from the same population have the same level of utility $\left(U_{11}=U_{12}, U_{21}=U_{22}\right)$ for $0<n_{12}, n_{21}<1$ or:
4.a
$X_{11}^{\beta}+Y_{11}^{\beta}=X_{12}^{\beta}+Y_{12}^{\beta}$
$4 . b$
$X_{21}^{\beta}+Y_{21}^{\beta}=X_{22}^{\beta}+Y_{22}^{\beta}$

Taking into account the Walras Law, we have 14 equations (1.a-1.e, 2.a-2.e, 3.a, 3.b,4.a,4.b) with 14 unknowns $\left(n_{11}, n_{12}, n_{21}, n_{22}, X_{11}, Y_{11}, X_{12}, Y_{12}, X_{21}, Y_{21}, X_{22}, Y_{22}, P_{1}\right.$, $P_{2}$ ). This system can be reduced to a two equations system with two unknowns (for proof see the appendix):

$$
\begin{aligned}
& \left(\frac{1-n_{11}+\alpha \cdot n_{22}}{n_{11}+\alpha \cdot\left(1-n_{22}\right)}\right)^{\beta}-\left(\frac{\left(\frac{y}{x} \frac{\left(1-n_{22}\right)\left(1-n_{22}+\alpha \cdot n_{11}\right)}{n_{11}\left(n_{11}+\alpha \cdot\left(1-n_{22}\right)\right)}\right)^{\beta}+1}{\left(\frac{y}{x} \frac{n_{22}\left(n_{22}+\alpha \cdot\left(1-n_{11}\right)\right)}{\left(1-n_{11}\right)\left(\left(1-n_{11}\right)+\alpha \cdot n_{22}\right)}\right)^{\beta}+1}\right)^{1-\beta}=0 \\
& \left(\frac{\left(1-n_{22}\right)\left(1-n_{11}\right)}{n_{11} n_{22}}\right)^{\frac{1-\beta}{\beta}}-\frac{\left(\left(1-n_{11}\right)+\alpha \cdot n_{22}\right)\left(\left(1-n_{22}\right)+\alpha \cdot n_{11}\right)}{\left(n_{22}+\alpha \cdot\left(1-n_{11}\right)\right)\left(n_{11}+\alpha \cdot\left(1-n_{22}\right)\right)}=0
\end{aligned}
$$

In order to solve for $n_{11}$ and $n_{22}$ we minimize the sum of the square of the lefthand sides of equation (4) and (5) (denoted by $z$ ) with respect to $n_{11}$ and $n_{22}$. Figure 1 shows the variation of $z$. 


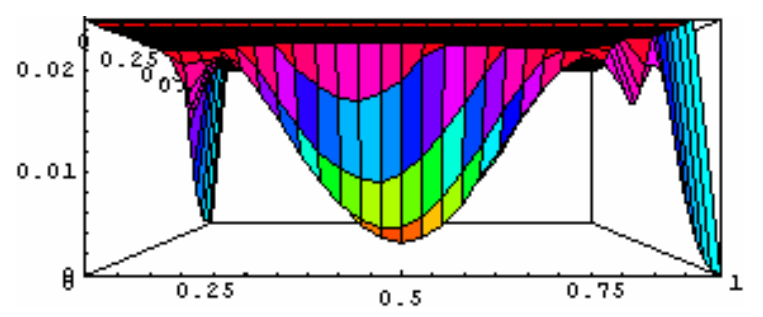

Figure 1. Variation of the objective function $z$ (on the vertical axis) as $n_{11}$ and $n_{22}$ (on the horizontal axes) vary from 0 to 1 .

We note from equation (4) that the internal migration equilibrium depends on the ratio $y / x$ rather than on the levels of $y$ and $x$ in each island. The unique internal solution is $n_{11}=n_{12}$ $=n_{21}=n_{22}=0.5$, as shown in Figure 1. There are also two corner solutions where $P_{1}=$ $P_{2}$ in equations $1 a, 1 b, 2 a, 2 b$, where $1 c, 1 d, 2 c, 2 d, 3 a$ and $3 b$ hold, where $X_{1 j}+X_{2 j}=x(1+\alpha)$ replaces $1 e$ and $2 e$, and $Y_{1 j}+Y_{2 j}=y(1+\alpha)$ replaces $1 f$ and $2 f$, and where $4 a$ and $4 b$ do not hold. The solutions are: (C1) $n_{11}=1, n_{22}=0$; and (C2) $n_{11}=0, n_{22}=1$.

We can compute the prices with equations $A .9$ and A.10, in the Appendix, and the consumption and utility levels with equations $A .1-A .8$.

For the internal migration equilibrium with $n_{11}=n_{22}=0.5$ utility is:

$$
\begin{aligned}
& U_{11}^{I}=U_{12}^{I}=\left(\frac{1+\alpha}{2}\right)^{\beta} x^{\beta^{2}}\left(x^{\beta}+y^{\beta}\right)^{1-\beta} \\
& U_{21}^{I}=U_{22}^{I}=\left(\frac{1+\alpha}{2}\right)^{\beta} y^{\beta^{2}}\left(x^{\beta}+y^{\beta}\right)^{1-\beta}
\end{aligned}
$$

Both corner solutions generate the same utility levels. Utility for the Island 1 corner solution is:

$$
\begin{aligned}
& U_{11}^{C}=(1+\alpha)^{\beta} x^{\beta^{2}}\left(x^{\beta}+y^{\beta}\right)^{1-\beta} \\
& U_{21}^{C}=(1+\alpha)^{\beta} y^{\beta^{2}}\left(x^{\beta}+y^{\beta}\right)^{1-\beta}
\end{aligned}
$$


The internal equilibrium and the corner solutions generate the same relative price. The difference between the levels of consumption and utility is due to differences in social capital. For both population groups, the social capital for the internal equilibrium is $\frac{1+\alpha}{2}$ while for the corner solutions, it is $1+\alpha$. The utilities ratio is $U_{i j}^{C} / U_{i j}^{I}=2^{\beta}>1, i$, $j=1,2$. Thus the level of utility is higher for corner solutions than for the internal one.

We now compare the initial utility level with that of the internal equilibrium:

$$
\frac{U^{I}}{U^{0}}=\frac{\left(x^{\beta}+y^{\beta}\right)^{1-\beta}}{\left(x^{\beta}\right)^{1-\beta}}\left(\frac{1+\alpha}{2}\right)^{\beta}
$$

The first term is greater than 1 and the second is smaller than 1 . Thus, the impact is ambiguous a priori. For $\beta=1$, there are no diversity gains and the ratio is $\frac{1+\alpha}{2} \leq 1$. Thus, migration leads to a welfare loss if there are no diversity gains, except when the two populations have identical social capital $(\alpha=1)$, in which case migration has no impact on welfare. From equation (10), it follows that welfare gains from migration increase with $\alpha$ and fall with $\beta$.

\section{Trade}

We consider the situation in which people cannot migrate but they can trade. In this situation, there is one price in both islands and both goods are available in both islands. People from Island 1 (2) maximize $U_{11}\left(U_{22}\right)$.

The first order conditions are:

$$
X_{11}=Y_{11} P_{1}^{\frac{1}{\beta-1}}
$$




$$
X_{22}=Y_{22} P_{1}^{\frac{1}{\beta-1}}
$$

The budget constraints are:

$$
P_{1} X_{11}+Y_{11}=P_{1} x
$$

(14)

$$
P_{1} X_{22}+Y_{22}=y
$$

The market clearing conditions are: ${ }^{7}$

$$
\begin{aligned}
& x=X_{11}+X_{22} \\
& y=Y_{11}+Y_{22}
\end{aligned}
$$

We can eliminate $X_{11}$ and $X_{22}$ from (15) using first order conditions (11) and (12):

$$
x=\left(Y_{11}+Y_{22}\right) P_{1}^{\frac{1}{\beta-1}}
$$

Using (16), we can express the price:

$$
P_{1}=\left(\frac{y}{x}\right)^{1-\beta}
$$

From (11), (13) and (18) we obtain consumption for Island 1 and similarly for Island 2.

The utilities under free trade are:

$$
U_{11}^{t}=x^{\beta^{2}}\left(x^{\beta}+y^{\beta}\right)^{1-\beta}
$$

$$
U_{22}^{t}=y^{\beta^{2}}\left(x^{\beta}+y^{\beta}\right)^{1-\beta}
$$

\footnotetext{
${ }^{7}$ Due to Walras Law we just keep one equation.
} 


\section{Comparing the Migration and the Trade Solutions}

We use the notation of $U_{1}\left(U_{2}\right)$ for the utility of the native population in Island 1 (2) in equilibrium From the relations (10),(14) and (19) we obtain the following inequalities (and similarly for the second island):

$$
\begin{aligned}
& U_{1}^{C}>U_{1}^{t}>U_{1}^{I} \\
& U_{2}^{C}>U_{2}^{t}>U_{2}^{I}
\end{aligned}
$$

The intuition for these results is that utility is higher when society benefits from product diversity and social capital. Populations benefit from the same level of product diversity under the three solutions. However, the level of social capital differs under these solutions. When both populations are on the same island, social capital $S=1+\alpha$. Trade, with $S=1$, is a second best. The internal equilibrium, with social capital $S=(1+\alpha) / 2$, has the lowest utility.

It is interesting to compare social inequality across the two population groups under all these situations. In the initial situation we have:

$$
\frac{U_{1}^{0}}{U_{2}^{0}}=\left(\frac{x}{y}\right)^{\beta}
$$

For the migration and trade situations we have:

$$
\frac{U_{1}^{C}}{U_{2}^{C}}=\frac{U_{1}^{t}}{U_{2}^{t}}=\frac{U_{1}^{I}}{U_{2}^{I}}=\left(\frac{x}{y}\right)^{\beta^{2}}
$$

Thus, both migration and trade reduce world inequality. 


\section{Migration Dynamics}

With multiple migration solutions, we further differentiate between them by introducing a dynamic system. Consider

$$
\left\{\begin{array}{l}
\dot{n}_{12}=U_{12}-U_{11} \\
\dot{n}_{21}=U_{21}-U_{22}
\end{array}\right.
$$

where the change in the proportion of the population that migrates from one island to the other is equal to the difference between the utility of a migrant and the utility of an individual that stays at home. The equality of utility, $U_{12}=U_{11}$ and $U_{21}=U_{22}$, corresponds to a critical point for the dynamic system, and, from the preceding discussion, it is an equilibrium condition for the system (4.a and 4.b) and corresponds to $n_{12}=0.5$ and $n_{21}=0.5$. The dynamic system is nonlinear and does not have a closed form solution but we can analyze the behavior of the system around the critical point by linearization. We find that for the same human capital $(x=y)$, for small $\alpha$ and for $\beta$ close to 1 , the internal migration equilibrium is a negative attractor, and for other values of $\alpha$ and $\beta$ it is a saddle point. Thus, for both situations the equilibrium is unstable.

Let us consider the values of $\alpha=0.5$ and $\beta=0.5$. If $U_{12}-U_{11}$ is positive then $n_{12}$ is increasing, and there is migration of population 1 from Island 1 to Island 2. If $U_{12}-U_{11}$ is negative then $n_{12}$ is decreasing, and the migrants are returning to their own island, with a similar discussion for $n_{21}$. From Figure 2 we note that the internal migration equilibrium is a saddle point and therefore unstable, and the corner solutions are stable points. 
Figure 2. Internal migration equilibrium is a saddle point, therefore unstable, and the corner solutions are stable points.

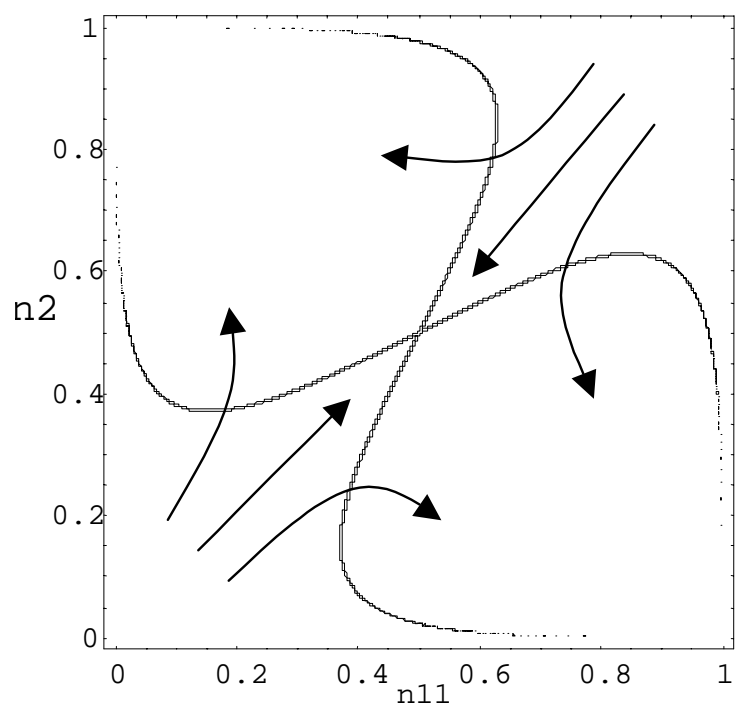

The dynamic system (25) is well defined as long as the utilities are well defined. To compute the utilities, we need finite prices and this implies the existence of migration. How can we define the dynamic system in the initial situation, before migration takes place? We can imagine a two step process. In the first stage, the first migrant move to the other island. ${ }^{8}$ In the second stage, migration is governed by the dynamic system.

We consider three situations for the first stage; (1) $n_{12}>n_{21}$; (2) $n 12=n_{21}$; (3) $n_{12}$ $<n_{21}$. When we consider the same amount of human capital for both islands $(x=y)$ the results are symmetric (Figure 3). The bold curves are numerically computed solutions and correspond to the three situations in the first stage (we choose for the first stage: (1) $n_{12}=\frac{\sqrt{3}}{10}, n_{21}=\frac{1}{10} ;$ (2) $n_{12}=\frac{\sqrt{2}}{10}, n_{21}=\frac{\sqrt{2}}{10} ;$ (3) $n_{12}=\frac{1}{10}, n_{21}=\frac{\sqrt{3}}{10}$ ). In case (1), migration is higher from Island 1 to Island 2 than from Island 2 to Island 1 . This results in

\footnotetext{
${ }^{8}$ We do not consider transportation costs in this model but it seems reasonable to assume that it is prohibitively expensive to move large populations from one island to another at the beginning of the migration, so for the first step we consider small values for $\mathrm{n}_{12}$ and $\mathrm{n}_{21}$.
} 
$S_{22}>S_{11}$ and $S_{12}>S_{21}$. This implies a higher output in Island 2 than in Island 1 for both populations and therefore a faster migration $\dot{n}_{12}$ than $\dot{n}_{21}$. Thus everybody ends up on Island 2 in a stable equilibrium $\left(n_{12}=1, n_{21}=0\right)$. In case (2), $U_{12}-U_{11}=U_{21}-U_{22}$ and we obtain a similar migration pattern for the two populations, ending in an unstable equilibrium $\left(n_{12}=0.5, n_{21}=0.5\right)$. Case (3) is symmetric with case (1), with $n_{12}=0, n_{21}=$ 1. Note that in cases (1) and (3), there is an intermediate range (for values of $n_{12}$ in case (1) and $n_{21}$ in case (2) between 0.35 and 0.75 in Figure 3) where we obtain return migration.

Figure 3.The migration trajectories for the same amount of human capital $(x=y)$.

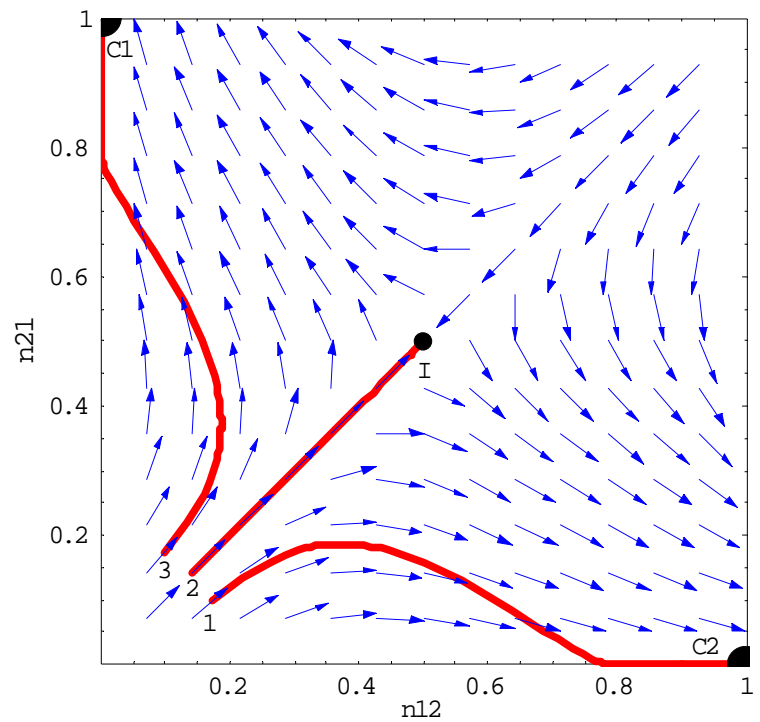

One can repeat the exercise with $x \neq y$, i.e., with different levels of human capital for the two populations and the same three cases as in the first stage. ${ }^{9}$ Figure 4 depicts the case $x=1, y=100$. In case (3), when more people migrate from Island 2 to Island 1 than population 1 migrates to Island 2, the very high level of human capital for population 2 in

\footnotetext{
${ }^{9}$ The initial values for $n_{12}$ and $n_{21}$ for the three cases are the same as in the equal amount of human capital case.
} 
Island 2 more than compensates for the social capital loss, and the gains in utility for the migrants from Island 1 are higher than the corresponding gains for the migrants from Island 2, so both populations end up in Island 2. In other words, if the assumptions of the model are satisfied, there is free migration, migration starts with reasonably small movements of people, and there are significant differences in human capital between populations, then the population with lower human capital migrates to the island with the population with higher human capital. Given that everyone ends up in Island 2 under case (3), everyone must also end up in Island 2 in cases (2) and (3), as is shown in Figure 4.

Figure 4. The migration trajectories for higher level of human capital for population 2 of Island $2(x=1, y=100)$.

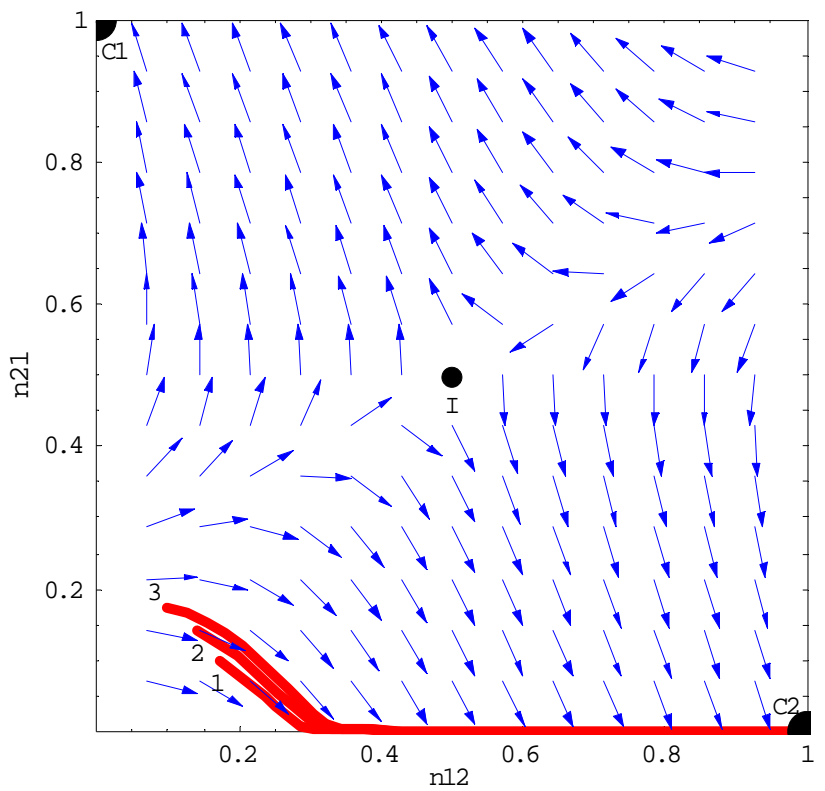

\section{8. $\underline{\text { Conclusion }}$}

This paper presents a general equilibrium model of migration, human capital and social capital. We find that there are three equilibrium solutions: an internal one with half the population of each country migrating to the other country, and two corner solutions 
where everyone ends up in one of the two countries. The internal solution is unstable and is unlikely to be reached under different levels of human capital across the two countries. The corner solutions are stable and will be reached under most circumstances. Welfare under any of the equilibrium solutions rises with the increase in the diversity in human capital and decreases with the diversity in social capital between migrants and natives. Either of the two corner solutions maximizes world welfare. These solutions are obtained if migration is unconstrained but there are high human capital differences - in which case everyone ends up in the country with the highest initial level of human capital - or, if immigration is fully restricted by one of the two countries. In the presence of social capital, migration restrictions by one country maximize world welfare.

In addition, trade and migration are not equivalent if social capital is present. Welfare increases with free trade and is higher than under the internal migration solution and lower than under the corner solutions. Both trade and migration reduce inequality between the populations of the two countries. 


\section{References}

Bauer, T.K. and A. Kunze. 2004. "The Demand for High-Skilled Workers and Immigration Policy," Institute for the Study of Labor (IZA) Discussion Paper No. 999.

Coleman, J.S. 1988. "Social Capital in the Creation of Human Capital," American Journal of Sociology 94 (Supplement): S95-S120.

Corden, W.M. 2003. "40 Million Aussies? The Immigration Debate Revisited,” Inaugural Richard Snape Lecture, Productivity Commission, Melbourne.

Glaeser, E. L.,, D. Laibson, J.A. Scheinkman, and C.L. Soutter. 2000. "Measuring Trust," Quarterly Journal of Economics, 115 (3):811-46.

Jacobson, M.F. 1998. Whiteness of a Different Color: European Immigrants and the Alchemy of Race. Harvard University Press: Cambridge.

Lazear, E.P. 2000. "Culture and Language" in Essays in Honor of Gary S. Becker. Journal of Political Economy 107 (6): S95-126. Part 2.

Schiff, M. 1992. "Social Capital, Labor Mobility, and Welfare: The Impact of Uniting States," Rationality and Society 4: 157-175.

Schiff, M. 1998. "Integration Politique, Mobilite de la Main d'Oeuvre, Bien-etre et Capital Socio-Culturel," Revue d'economie du developpement. 6 (4).

Schiff, M. 2002. "Love thy Neighbor: Trade, Migration, and Social Capital," European Journal of Political Economy, 18 (1):87-107

Schiff, M. 2004. "Labor Mobility, Trade and Social Capital," Review of International Economics (September). Forthcoming.

Schiff, M. and L. A. Winters. 1998. "Regional Integration as Diplomacy," World Bank Economic Review 12(2): 271-96. 


\section{$\underline{\text { Appendix }}$}

Assuming that there is migration for both islands $\left(n_{11} \neq 1\right.$ and $n_{22} \neq 1$ so $n_{12} \neq 0$ and $n_{21} \neq 0$ and $\left.0<P_{1}, P_{2}<\propto\right)$, we reduce the initial systems of 14 equations (1.a-1.e, 2.a-2.e, 3.a, 3.b,4.a,4.b) with 14 unknowns $\left(n_{11}, n_{12}, n_{21}, n_{22}, X_{11}, Y_{11}, X_{12}, Y_{12}, X_{21}, Y_{21}\right.$, $\left.X_{22}, Y_{22}, P_{1}, P_{2}\right)$ to a system of two equations with two unknowns.

From first order condition (1.a) and budget constraint (1.c) we can write $X_{11}$ and $Y_{11}$ as a function of price $P_{1}$ and $n_{11}, n_{21}$ :

A.1

$$
X_{11}=\frac{P_{1}^{\frac{\beta}{\beta-1}} x\left(n_{11}+\alpha \cdot n_{21}\right)}{P_{1}^{\frac{\beta}{\beta-1}}+1}
$$

$$
Y_{11}=\frac{P_{1} x\left(n_{11}+\alpha \cdot n_{21}\right)}{P_{1}^{\frac{\beta}{\beta-1}}+1}
$$

In a similar way we can express the other consumption terms:

$$
X_{12}=\frac{P_{2}^{\frac{\beta}{\beta-1}} x\left(n_{12}+\alpha \cdot n_{22}\right)}{P_{2}^{\frac{\beta}{\beta-1}}+1}
$$

A.4

$$
Y_{12}=\frac{P_{2} x\left(n_{12}+\alpha \cdot n_{22}\right)}{P_{2}^{\frac{\beta}{\beta-1}}+1}
$$

$$
X_{21}=\frac{P_{1}^{\frac{1}{\beta-1}} y\left(n_{21}+\alpha \cdot n_{11}\right)}{P_{1}^{\frac{\beta}{\beta-1}}+1}
$$

A.6

$$
Y_{21}=\frac{y\left(n_{21}+\alpha \cdot n_{11}\right)}{P_{1}^{\frac{\beta}{\beta-1}}+1}
$$

A. 7

$$
X_{22}=\frac{P_{2}^{\frac{1}{\beta-1}} y\left(n_{22}+\alpha \cdot n_{12}\right)}{P_{2}^{\frac{\beta}{\beta-1}}+1}
$$

A. 8

$$
Y_{22}=\frac{y\left(n_{22}+\alpha \cdot n_{12}\right)}{P_{2}^{\frac{\beta}{\beta-1}}+1}
$$


We can use $A .1$ and $A .5$ to eliminate the consumption terms $X_{11}$ and $X_{21}$ from the market clearing equation 1.e and to express the price $P_{1}$ as a function of $n_{11}$ and $n_{21}$ :

$$
P_{1}=\left(\frac{y}{x} \frac{n_{21}\left(n_{21}+\alpha \cdot n_{11}\right)}{n_{11}\left(n_{11}+\alpha \cdot n_{21}\right)}\right)^{1-\beta}
$$

In a similar way we can write $P_{2}$ as a function of $n_{12}$ and $n_{22}$ :

$$
P_{2}=\left(\frac{y}{x} \frac{n_{22}\left(n_{22}+\alpha \cdot n_{12}\right)}{n_{12}\left(n_{12}+\alpha \cdot n_{22}\right)}\right)^{1-\beta}
$$

Until now we did not use the migration equilibrium equations (4.a and 4.b) and population identity (3.a and $3 . b)$. We can use the equations $A .1-A .4$ to eliminate the consumption terms $X_{11}, Y_{11}, X_{12}, Y_{12}$ from the migration equilibrium equation 4.a and after some manipulations we can write:

A.11

$$
\left(\frac{n_{12}+\alpha \cdot n_{22}}{n_{11}+\alpha \cdot n_{21}}\right)^{\beta}=\left(\frac{P_{1}^{\frac{\beta}{1-\beta}}+1}{P_{2}^{\frac{\beta}{1-\beta}}+1}\right)^{1-\beta}
$$

We can now use the equations $A .9$ and $A .10$ to eliminate the prices $P_{1}$ and $P_{2}$ and we obtain:

A.12

$$
\left(\frac{n_{12}+\alpha \cdot n_{22}}{n_{11}+\alpha \cdot n_{21}}\right)^{\beta}=\left(\frac{\left(\frac{y}{x} \frac{n_{21}\left(n_{21}+\alpha \cdot n_{11}\right)}{n_{11}\left(n_{11}+\alpha \cdot n_{21}\right)}\right)^{\beta}+1}{\left(\frac{y}{x} \frac{n_{22}\left(n_{22}+\alpha \cdot n_{12}\right)}{n_{12}\left(n_{12}+\alpha \cdot n_{22}\right)}\right)^{\beta}+1}\right)^{1-\beta}
$$

In a similar way, we can use the equations $A .5-A .8$ to eliminate the consumption terms $X_{21}, Y_{21}, X_{22}, Y_{22}$ from the migration equilibrium equation $4 . b$ and after some manipulations we can write: 
A.13 $\left(\frac{n_{22}+\alpha \cdot n_{12}}{n_{21}+\alpha \cdot n_{11}}\right)^{\beta}=\left(\frac{P_{1}^{\frac{\beta}{\beta-1}}+1}{P_{2}^{\frac{\beta}{\beta-1}}+1}\right)^{1-\beta}$

The right-hand side can be transformed using equation $A .11$ and we can further use the equations $A .9$ and $A .10$ to eliminate the prices $P_{1}$ and $P_{2}$ and we obtain:

A.14 $\left(\frac{n_{21} n_{12}}{n_{11} n_{22}}\right)^{\frac{1-\beta}{\beta}}=\frac{\left(n_{12}+\alpha \cdot n_{22}\right)\left(n_{21}+\alpha \cdot n_{11}\right)}{\left(n_{22}+\alpha \cdot n_{12}\right)\left(n_{11}+\alpha \cdot n_{21}\right)}$

We can use the population identity (3.a and 3.b) to eliminate $n_{12}$ and $n_{21}$ from the equations $A .12$ and $A .14$ and we obtain a system of two equations with two unknowns:

A.15

$$
\begin{aligned}
& \left(\frac{1-n_{11}+\alpha \cdot n_{22}}{n_{11}+\alpha \cdot\left(1-n_{22}\right)}\right)^{\beta}=\left(\frac{\left(\frac{y}{x} \frac{\left(1-n_{22}\right)\left(1-n_{22}+\alpha \cdot n_{11}\right)}{n_{11}\left(n_{11}+\alpha \cdot\left(1-n_{22}\right)\right)}\right)^{\beta}+1}{\left(\frac{y}{x} \frac{n_{22}\left(n_{22}+\alpha \cdot\left(1-n_{22}\right)\right)}{\left(1-n_{11}\right)\left(\left(1-n_{11}\right)+\alpha \cdot n_{22}\right)}\right)^{\beta}+1}\right)^{1-\beta} \\
& \left(\frac{\left(1-n_{22}\right)\left(1-n_{11}\right)}{n_{11} n_{22}}\right)^{\frac{1-\beta}{\beta}}=\frac{\left(\left(1-n_{11}\right)+\alpha \cdot n_{22}\right)\left(\left(1-n_{22}\right)+\alpha \cdot n_{11}\right)}{\left(n_{22}+\alpha \cdot\left(1-n_{11}\right)\right)\left(n_{11}+\alpha \cdot\left(1-n_{22}\right)\right)}
\end{aligned}
$$

Lemma. If $(u, v)$ is a solution for the system of equations $A .15$ and $A .16$ in the space $\left(n_{11}\right.$, $\left.n_{22}\right)$ then $(1-u, 1-v)$ is also a solution.

Proof. If $(u, v)$ is a solution then:

A.17

$$
\begin{aligned}
& \left(\frac{1-u+\alpha \cdot v}{u+\alpha \cdot(1-v)}\right)^{\beta}=\left(\frac{\left(\frac{y}{x} \frac{(1-v)(1-v+\alpha \cdot u)}{u(u+\alpha \cdot(1-v))}\right)^{\beta}+1}{\left(\frac{y}{x} \frac{v(v+\alpha \cdot(1-u))}{(1-u)((1-u)+\alpha \cdot v)}\right)^{\beta}+1}\right)^{1-\beta} \\
& \left(\frac{(1-v)(1-u)}{v \cdot u}\right)^{\frac{1-\beta}{\beta}}=\frac{((1-u)+\alpha \cdot v)((1-v)+\alpha \cdot u)}{(v+\alpha \cdot(1-u))(u+\alpha \cdot(1-v))}
\end{aligned}
$$

If we plug $(1-u, 1-v)$ in $A .15$ and $A .16$ we have: 


$$
\begin{aligned}
& \left(\frac{u+\alpha \cdot(1-v)}{1-u+\alpha \cdot v}\right)^{\beta}=\left(\frac{\left(\frac{y}{x} \frac{v(v+\alpha \cdot(1-u))}{(1-u)((1-u)+\alpha \cdot v)}\right)^{\beta}+1}{\left(\frac{y}{x} \frac{(1-v)((1-v)+\alpha \cdot u)}{u(u+\alpha \cdot(1-v))}\right)^{\beta}+1}\right)^{1-\beta} \\
& \left(\frac{v \cdot u)}{(1-v) \cdot(1-u)}\right)^{\frac{1-\beta}{\beta}}=\frac{(u+\alpha \cdot(1-v))(v+\alpha \cdot(1-u))}{((1-v)+\alpha \cdot u)((1-u)+\alpha \cdot v)}
\end{aligned}
$$

We notice that the inverse of the left-hand side of $A .19$ is the left-hand side of $A .17$ and the inverse of the right-hand side of $A .19$ is the right-hand side of $A .17$, so $A .19$ is true. Similarly for $A$. 20, so (1-u, $1-v)$ is a solution for $A .15$ and $A .16$.

There is a direct interpretation for this result. If $(u, v)$ is a migration equilibrium, then we have $(u, 1-v)$ on Island 1 and $(1-u, v)$ on Island 2 and the utilities are the same for the same population. If we switch to solution $(1-u, 1-v)$, we have $(1-u, v)$ on Island 1 and $(u, 1-v)$ on Island 2 and the utilities are the same for the same populations, so $(1-u, 1-v)$ is a migration equilibrium too. This suggests that if we have the same combination of populations on both islands then the amount of social capital will be the same and the utility will be the same, so this is an equilibrium. We can check that $n_{11}=.5$ and $n_{22}=.5$ is a solution for the system of equations $A .15$ and $A .16$ so this is a migration equilibrium. When we reduce the initial system of 14 equations to 2 equations, we assume that there is migration in both islands. Let us relax this assumption and consider the corner solutions in which one or both islands does not have migration. If there is an island that is producing just one product, then there is an incentive for migration from the other island, so this is not equilibrium. If everybody from one island is moving to the other island, then there are gains both from diversity of consumption and social capital, so $n_{11}=1$ and $n_{22}=0$ and also $n_{11}=0$ and $n_{22}=1$ are migration equilibriums too. 